\title{
A Systematic Approach to Assess Forest Regeneration
}

\author{
by
}

\author{
David G. Brand ${ }^{1}$
}

\section{Abstract}

As the area of second-growth and man-made forest increases, successful management will require increasingly efficient methods of data collection and use. Developing plantation assessment systems requires the definition of what information is useful in decision-making, how best to collect that information, and how best to present it to the decision-maker or forester. In this paper a system is described that processes field survey data collected by a portable datalogger through a relay of software programs. The programs provide data summary, free-growing projection, application of a new spatial pattern statistic, and use of a Geographic Information System (GIS) for map production. The information generated will allow a forester to define whether the area needs brush control or fill planting, and whether those problems are localized (i.e. in brushy patches, or unstocked holes in the plantation) or spread through the entire area surveyed. The systematic collection and processing of survey data can also lead to the development of whole-forest silviculture planning models, comparing the estimated opportunities for growth and yield enhancement on a diversity of regenerating areas with economic criteria.

\section{Résumé}

A mesure que la superficie des jeunes peuplements forestiers et des forêts artificielles augmentera, il faudra employer des méthodes de plus en plus efficaces de collecte et d'utilisation de données pour garantir leur bonne gestion. II faut mettre au point des systèmes efficaces d'aide à la décision, en particulier au stade de la régénération, pour s'assurer que les dépenses engagées pour la gestion forestière se traduisent par des rendements optimaux dans les peuplements de croissance libre aux sites les plus productifs. Le présent rapport décrit un système de traitement de l'information recueillie sur le terrain au moyen d'un enregistreur de données portable par l'intermédiaire d'un ensemble de logiciels. Ces derniers permettent de résumer l'information, de faire des projections des peuplements en croissance libre, d'établir des statistiques sur la configuration spatiale et d'utiliser un système d'information géographique (SIG) pour l'établissement de cartes. L'analyse dans les meilleurs délais de la régénération des forêts sur les plans de la productivité et de la configuration spatiale peut permettre l'élaboration de modèles de planification sylvicole à l'échelle de forêts entières et la prise en compte de critères économiques dans l'étude des possibilités anticipées d'amélioration de la croissance et des rendements.

\section{Introduction}

Repeated silviculture surveys designed to assess stocking, survival, brush competition, or regeneration performance are time consuming and labour intensive. Often, an area is surveyed three or four times to yield relatively single-purpose information used to determine whether an area should be released from competition or fill-planted, or to determine growth performance and stocking for yield prediction purposes. Decisions are usually based on relatively simple statistics (mean, standard error). The limited scope of most surveys was necessary when statistics were calculated by hand. The availability of microcomputers and GIS software now makes it possible to automatically analyze and summarize data generated in the field, to tie into secondary

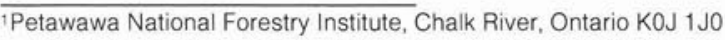

projection or diagnostic models, and to present the results in geographical form. This new capability requires forest managers to look again at what information they need to make silvicultural decisions effectively and to design systems of data collection and processing to provide that information. In this paper, I introduce some new sources of decision-making information and show how they can be integrated into a field survey and data analysis system.

\section{The Regeneration Assessment}

A regeneration assessment, at which point a forest manager must decide whether the regeneration or renewal phase of silviculture has been successful or needs remedial treatment, has largely been defined in Canada by provincial performance standards. In effect, however, universal standards do not reflect site differences and are classic examples of the law of the average - too much effort is expended on the marginal sites and effective management 


\section{FOREST-LEVEL FRAMEWORK FOR ASSESSING FOREST REGENERATION}

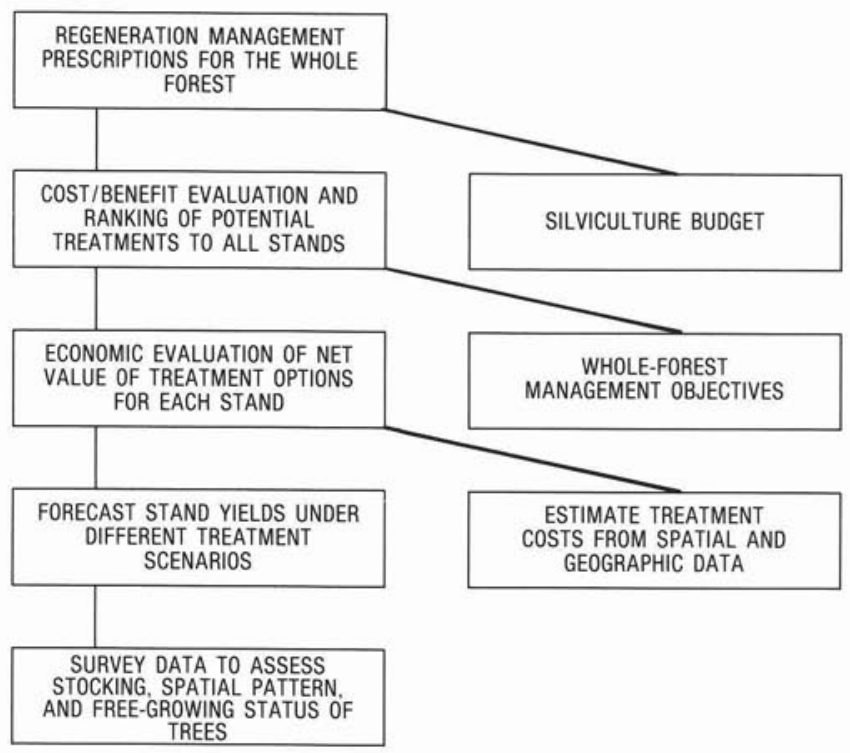

Figure 1. A decision tree for effective allocation of regeneration silviculture expenditure.

opportunities are missed on the better sites. The free-growing assessment, as these surveys are commonly called, is only a biological decision at the individual tree level. At the stand level, regeneration assessment is a complex decision-making process including a consideration of stocking, competition stress, growth performance, and opportunities for yield enhancement. Assessment of regeneration success is a relative judgement at the forest level, depending on an economic analysis of the costs and benefits of different treatments such as brush control, fill-planting and, in some regions, juvenile spacing. Further, the prescription is influenced by the funds available and often depends on ranking a series of sites to effectively meet program or timber supply targets.

To provide the basic information that underlies such a forest level assessment requires an estimate of the stock of trees that are free-growing, the potential improvement in spatial pattern and stocking that would result from brush control, and the site productivity. This biological information can be applied in conjunction with data on access, block size, constraints on management, or any of a number of other considerations to decide whether or not treatment of a particular block is justifiable (Fig. 1).

To provide this basic biological information, data should be collected on stocking, the free-growing status of each tree, growth rate (or ecological features allowing inference of forest productivity), and the spatial pattern or distribution of these factors (to determine whether a given average stocking is uniform or irregular, for example). In effect, a multiple purpose survey is needed that collects data for a free-growing projection model, a regeneration stocking and performance summary routine, and a spatial pattern analysis. Where treatment proves viable, the survey data should be available for prescription development and generation of field maps. This is particularly important where only a portion of the block needs brush control or fill-planting.

\section{A Pilot System}

The purpose of a pilot system is to demonstrate concepts. In this case, the regeneration assessment system presented will indicate opportunities to improve other aspects of data use in forestry. The objectives of this particular system are to promote:

1) usage of a biologically meaningful definition of the freegrowing tree;

2) usage of a measure of spatial pattern, in addition to stocking, in interpreting free-growing survey results; and

3 ) the integrated use of data for stand level (e.g. prescription development) and forest level (treatment allocation) purposes (sensu Baskerville 1986).

\section{System Components}

The components used in this system include a field survey with an automatic data recorder that outputs data to a set of support programs. The first of these programs is a projection and summary model that outputs tables of total and free-growing stocking, competing vegetation, and height/age relationships for the free-growing trees. The second calculates the spatial location of survey plots in terms of $(x, y)$ coordinates and applies an autocorrelation statistic to determine the spatial pattern (eveness or irregularity) of total stocking and free-growing stocking. Finally, the third component of the system is a linkage with a GIS software package that plots the location of the survey plots color coded by total stocking and shaded by degree of brush suppression. Map titling includes stand (polygon) number, the total and free-growing stocking, and spatial autocorrelation of total and free-growing stocking.

\section{Data Collection}

All data collection is carried out using a Husky Hunter portable datalogger. The model used has an 8 by 40 character screen display and a memory of 352000 bytes (352 k). A program is written in Hunter Basic that prompts the surveyor for data input via a series of designed screen formats. The program allows for several functions, including administrative information on the area to be surveyed, plot data entry or deletion, review or editing of plot data, and data transmission to secondary device (e.g. IBM-PC).

The field survey can be carried out using either quadrattype surveys or fixed radius plots. The quadrat survey uses fixed area plots that are subdivided into four quadrants. Each quadrant is assessed for the presence or absence of a commercial tree species. The fixed radius plot, commonly $0.005 \mathrm{ha}$, is assessed for the total number of well-spaced commercially acceptable trees. The spacing between acceptable trees is commonly determined as that desired for some optimum density.

Two survey routines are available. The first, for use where brush competition is not considered a significant problem, simply prompts for the total height and current and previous height increments on each crop tree. The second and expanded routine additionally prompts for information used to judge whether a tree is free-growing. Initially it must be decided if the tree is currently suppressed by examining whether the tree is completely overtopped with competitor foliage (Fig. 2). A suppressed tree will not be projected as freegrowing by the support software, but its competitors are to be tallied for potential use in developing a brush control prescription. Trees that are currently not suppressed, but with 
Initial Condition
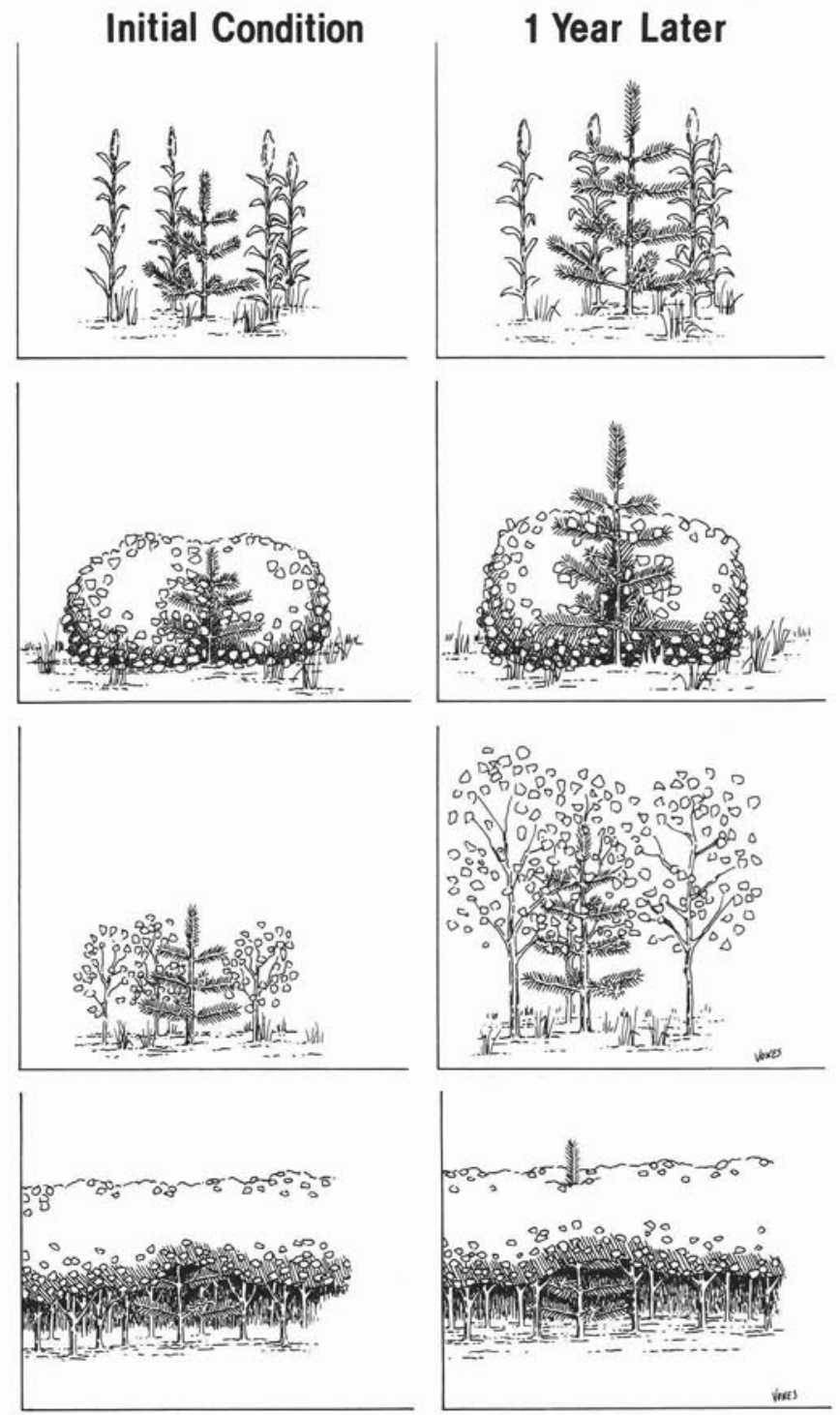

Figure 2. The free-growing threshold. In the field, trees with terminal leader shaded are suppressed and are not projected for free-growing status.

potentially more rapidly growing competitors, are also assessed for brush height and, in the case of shrub or tree competitors, brush height increment (Fig. 3).

When all trees in a plot have been tallied, the program prompts for bearing and distance to the next plot. This allows later determination of the location of each plot. Finally, the program carries a record from plot to plot of short form names for crop tree species and brush species. This is either loaded into the Hunter before the start of the survey, or is built up from plot to plot.

\section{The Free-growing Projection Model}

The free-growing projection routine is a FORTRAN program based on the algorithms discussed by Brand and Weetman (1986) for Douglas-fir. The model calculates the height ratio of the tree to the brush canopy. Then, based on the height growth trend of the tree and brush species, the model predicts the height ratio for the tree in the following year. If the
SUMMARY OF COMPETING VEGETATION* (Test Data)

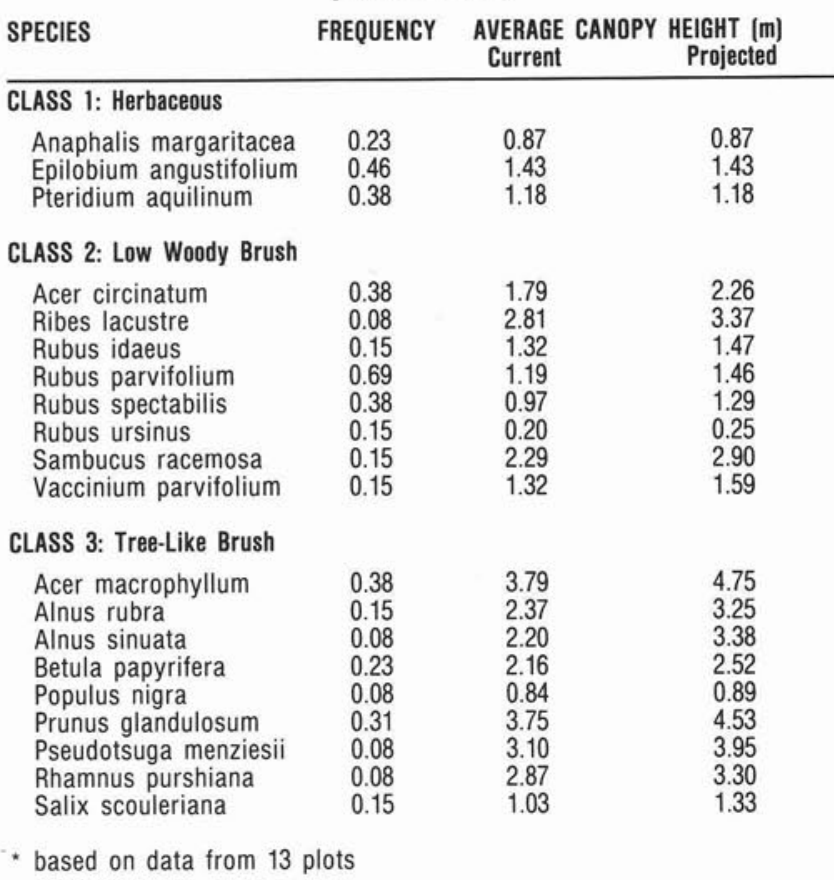

Figure 3. The dynamics of three classes of competing vegetation. In projecting free-growing status the growth pattern of the competitors and the tree must be taken into account.

tree: brush height ratio is projected to be increasing, the tree is considered free-growing. Further details of the algorithms used in the model are contained in Brand and Janas (1986).

Recent tests over two growing seasons near North Bay, Ontario with red pine and white spruce indicate that the model has a $90 \%$ success rate in predicting the free-growing status of trees. Because the model is based on the relative growth of trees and brush on the site being surveyed, the model is portable to any region of Canada where this type of freegrowing definition is desired.

\section{Plantation Performance}

Early performance data can be used to pinpoint establishment problems other than brush competition, or to make early estimates of site productivity for linkage with growth and yield models. In this system the height growth trend is developed for each species, with planted and natural trees calculated separately. The summary also presents the projected height growth for the site in the following growing season.

If the regeneration assessment survey is done after height growth increment has stabilized (generally age 5 to 8 , or total height greater than $1.5 \mathrm{~m}$ if planting check has been a problem) (cf. Brand and Weetman 1986. Thrower 1986, Omule and Krumlik 1987), a reasonable estimate of site index is possible. With stocking, stocking distribution, and site index available, the stand can be readily put onto a variable density type yield function for the species type concerned.

\section{Stocking Summary and Prescription Support}

To estimate the potential for benefit from silvicultural treatment, the stocking and amount of competition stress 


\section{STOCKING SUMMARY AND FREE TO GROW STATUS (Test Data)}

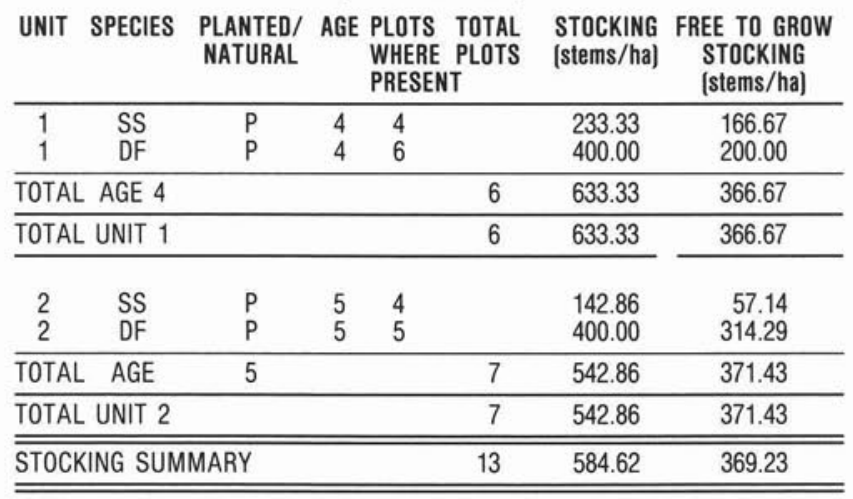

\section{TOTAL MEAN TREE HEIGHT FREE TO GROW TREES (m) (Test Data)}

$\begin{array}{llllll}1982 & 1983 & 1984 & 1985 & 1986 & \begin{array}{c}1987 \\ \text { PROJECTED }\end{array}\end{array}$

\begin{tabular}{|c|c|c|c|c|c|c|}
\hline \multicolumn{7}{|l|}{ Unit 1} \\
\hline $\begin{array}{l}\text { Sitka Spruce } \\
1986 \text { age }+4\end{array}$ & - & 0.40 & 0.64 & 0.99 & 1.51 & 2.16 \\
\hline $\begin{array}{l}\text { Douglas-Fir } \\
1986 \text { age }=4\end{array}$ & - & 0.33 & 0.59 & 0.92 & 1.47 & 2.10 \\
\hline Unit 2 & & & & & & \\
\hline $\begin{array}{l}\text { Sitka Spruce } \\
\quad 1986 \text { age }=5\end{array}$ & 0.41 & 0.71 & 1.12 & 1.63 & 2.43 & 3.33 \\
\hline $\begin{array}{l}\text { Douglas-Fir } \\
1986 \text { age }=5\end{array}$ & 0.33 & 0.57 & 0.91 & 1.50 & 2.24 & 3.20 \\
\hline
\end{tabular}

Figure 4. Output from the regeneration survey free-growing summary and projection model.

must be known. The data summaries from the free-growing model present stocking by species for total well-distributed commercial species and for that component of stocking that is projected as free-growing (Fig. 4). The comparison of total and free-growing stocking, then, indicates the opportunity to increase free-growing stocking by brush control treatment.

If brush control is desirable, the program also presents a summary of the competing vegetation species, their percentage cover, and their projected canopy height. This helps ensure that emerging brush problems are identified. The listing of brush species by species and group (herbaceous, shrub, and trees) permits decisions to be made regarding the type and timing of control treatments.

\section{Interpretation of Spatial Pattern in Stocking}

Both stocking and brush competition are rarely uniformly distributed within a regenerating area and this can have more important impact on yield than it would appear from stand average statistics. For example, an extreme case would be that a clear-cut with a stocking of 900 free-growing stems/ha could include a patch representing $30 \%$ of the area in which commercial species are completely suppressed. Examining the summary would suggest that regeneration had been successful (based on exceeding average minimum stocking) but, actually, $30 \%$ of the productive potential of the site would be lost. If the site were productive and economically appealing from a forestry investment perspective, this would be a serious error, causing both over-estimation of yield and lost opportunity for silvicultural correction.

Although such an extreme case is an exception, it points out that the distribution of stocking through the area surveyed is as important as total average stocking in determining opportunity for increasing yield through fill-planting, rehabilitation, or brush control. To improve the ability to assess this distribution or spatial pattern in total or free-growing stocking, a program was written to calculate a statistic that measures irregularity or patchiness in stocking. This statistic was developed as a measure of the spatial autocorrelation of any feature distributed over an area (see Cliff and Ord [1981] for detailed discussion) and has been used for analyzing such diverse things as cholera epidemics, settlement patterns, and the acceptance of government subsidies by farmers. It is calculated as:

$$
\text { [1] } \quad I=n / 2 A\left(\sum_{i} \underset{j}{\sum}\left(a_{i j} \cdot Z_{i} \cdot Z_{j}\right)\right) /\left(\sum_{i} Z_{i}^{2}\right)
$$

where $\mathrm{n}$ is the total number of plots in the block surveyed

$A$ is the total number of joins between plots (a join means that a plot and its neighbour are within some threshold distance of one another, such as $60 \mathrm{~m}$, for example). A given plot may have one or several joins depending on its location in the block; e.g., a plot near the edge of the block will have fewer joins than one in the middle of the block.

$a_{i j}$ is 1 if the ith and jth plots are joined and 0 if they are not

$x$ refers to the stocking of trees in any plot

$z_{i}=\left(x_{i}-x\right)$, where $x_{i}$ is the stocking of the plot being considered ( $x=$ mean stocking level of all plots)

$z_{j}=\left(x_{j}-x\right)$, where $x_{j}$ is the stocking of the neighbouring plot being considered

The statistic (I) determines whether neighbouring plots tend to be similar in stocking or are different. If stocking tends to be similar among neighbours, it is clumped or patchy. If different among neighbours, the variation in stocking is regular or well dispersed. Random patterns of stocking variation are spatially uncorrelated and have an I statistic value of 0 . At the extremes the statistic ranges from approximately +0.4 for completely uneven stocking (e.g. half the area surveyed has full stocking and half has none) to -0.4 where stocking variation is extremely regular (e.g. a pattern of pltos with regular change in stocking values - such as $4,8,4,8,4,8)$.

To gain some insight into the operation and interpretation of this statistic, the program was run on a number of hypothetical regeneration areas, with systematic variation of different factors relating to stocking. The factors examined were size, shape, and location of patches with poor stocking, and the degree of variation between the poorly stocked patch and its surrounding plots. The first factor considered was patch size and, as expected, the value of the I statistic increases as the size of the unstocked patch increases in a given area. The maximum I value occurs when the patch occupies half of the area surveyed. The shape of patch also affects the I statistic, as irregularly shaped patches have less positive effect on the value than regularly shaped patches. This is a function of the edge effect of irregular patches, and usefully, is biologically meaningful, as irregular holes in a forest would be more easily filled by surrounding tree crowns than regular (i.e. perfectly circular) shaped openings. 
The location of a patch in the regenerating area has no particular effect on the statistic, unless it is at the very edge of the block. In this case, the I statistic is slightly higher than if the patch was inside the block, because there are fewer neighbouring plots for a patch at the edge of an area surveyed. Again, this is a managerially appealing feature, since problem areas at the edge of blocks will not have surrounding trees of the same age class on all sides and will be less likely to be filled by crown growth of surrounding trees. As the number of patches of a given size increase within a block the I statistic decreases, tending towards 0.0 . This can be explained in terms of an increased randomness in stocking as areas of higher and lower stocking become more intermixed.

The degree of difference in stocking among patches and the influence of stocking variability are potentially more problematical. The statistic primarily considers each stocking level discretely. That is, a unit with stocking split between 0 and 1600 stems/ha (each representing half of the area surveyed) would have a very similar I value to one with stocking split between 800 and 1000 stems/ha. For example a plantation with approximately $22 \%$ of its area in a patch of lower stocking was studied (see Fig. $5 b$ ). The majority of the plantation had stocking of between 1200 and 1600 stems per hectare. If the stocking in the small patch is 0 for every plot, the I value is +.30 . However, if the stocking in the patch is 800 per hectare, a much better situation for forestry purposes, the I only diminishes to +.26 . In effect, the I statistic is not affected by the degree of difference or variability of the data.

Based on the results of these and other simulations, the program output was designed to present the I statistic and a listing of the proportion of plots in the area surveyed with each stocking level. This, then, allows better interpretation of the I statistic. For example, if there were no plots of less than 800 stems per hectare stocking, and yet there was positive spatial autocorrelation, spatial pattern could be ignored in decisionmaking. This is much less a problem in quadrat surveys, where plot stocking only varies between 0 and 4 . In fixed plot surveys, where a large number of stocking classes are available (e.g. $0-8$ trees/plot in a 1/200th ha plot survey), class grouping may be appropriate before calculating the I statistic. Table 1 presents an overview of the interpretation of stocking, stocking variability, and the I-statistic.

\section{Linkage with a Geographic Information System for Map Display}

Where the spatial pattern indicates that a treatment may only be needed in part of a large area, the plot information can be presented in geographical form to act as a field map. The spatial autocorrelation statistic uses as input a series of $(x, y)$ coordinates that need only be corrected for the UTM grid location of the first point. The total stocking of each plot is represented by colours, ranging from white for no trees present, to yellow and red for intermediate stocking levels, to blue for full stocking. In addition, the shade pattern is varied from solid colour for a plot with all trees free-growing to very pale shading for a plot with no trees free-growing. The result is a two dimensional depiction of stocking and level of brush competition within the block.

Figure 5 provides four examples of output from the system, demonstrating both the interpretation of the autocorrelation statistic and the map depiction of the information from the summary and projection models. In Figures $5 \mathrm{a}$ and $5 \mathrm{~b}$ all trees are free-growing and stocking is presented in solid colour. In Fig. 5a, the stocking is regularly distributed and the I-statistic is negative, but in Fig. $5 \mathrm{~b}$ a large section of the site is unstocked and the I-statistic is positive. Thus, the plantation in Fig. $5 b$, while apparently fully stocked by the average stocking ( $1127 /$ ha) could still benefit greatly from fill planting. The plantation in Fig. $5 \mathrm{a}$, on the other hand, would not be expected to show much yield enhancement if fill planted.

In Figures $5 \mathrm{c}$ and $5 \mathrm{~d}$ the total stocking is modified by brush competition to present a differential shade pattern of the colour representing total available stocking. Calculation of the I-statistic for both the total and free-growing stocking components indicates the impact brush control would have on not only mean stocking but on spatial pattern. For example areas with more spatial autocorrelation in free-growing stocking than in total stocking would be expected to benefit more from brush control. In Fig. 5c, while total stocking is low, the area where brush control would have greatest impact is also where the increased stocking is least needed. In this case brush control would cause an increase in stocking, but a poorer stocking distribution. In Fig. 5d, however, the converse is true. Brush competition problems are localized in areas of poor stocking, the usual case where brush control has been delayed. In this case, while brush control will only improve stocking on average by 85 trees per hectare $(710$ to 825 per hectare), it may improve total site yields by $20 \%$ to $25 \%$.

\section{Future Developments}

To improve the interpretation of the spatial autocorrelation statistic it is necessary to study how different degrees of positive or negative autocorrelation at an early age will affect

\begin{tabular}{|c|c|c|c|}
\hline $\begin{array}{l}\text { Stocking avg. } \\
\text { (stems/ha) }\end{array}$ & $\begin{array}{c}\text { Stocking } \\
\text { coefficient } \\
\text { of variation }\end{array}$ & I-statistic & Interpretation \\
\hline 400 & $90 \%$ & +0.30 & $\begin{array}{l}\text { poor stocking, highly variable and spatially correlated } \\
\text { - fill-plant }\end{array}$ \\
\hline 900 & $10 \%$ & +0.30 & $\begin{array}{l}\text { reasonable stocking, low variability, spatial autocorre- } \\
\text { lation not important }\end{array}$ \\
\hline 900 & $90 \%$ & +0.30 & $\begin{array}{l}\text { reasonable stocking, but highly variable and spatially } \\
\text { correlated }- \text { fill plant }\end{array}$ \\
\hline
\end{tabular}

Coefficiation of variation is standard deviation/mean. 


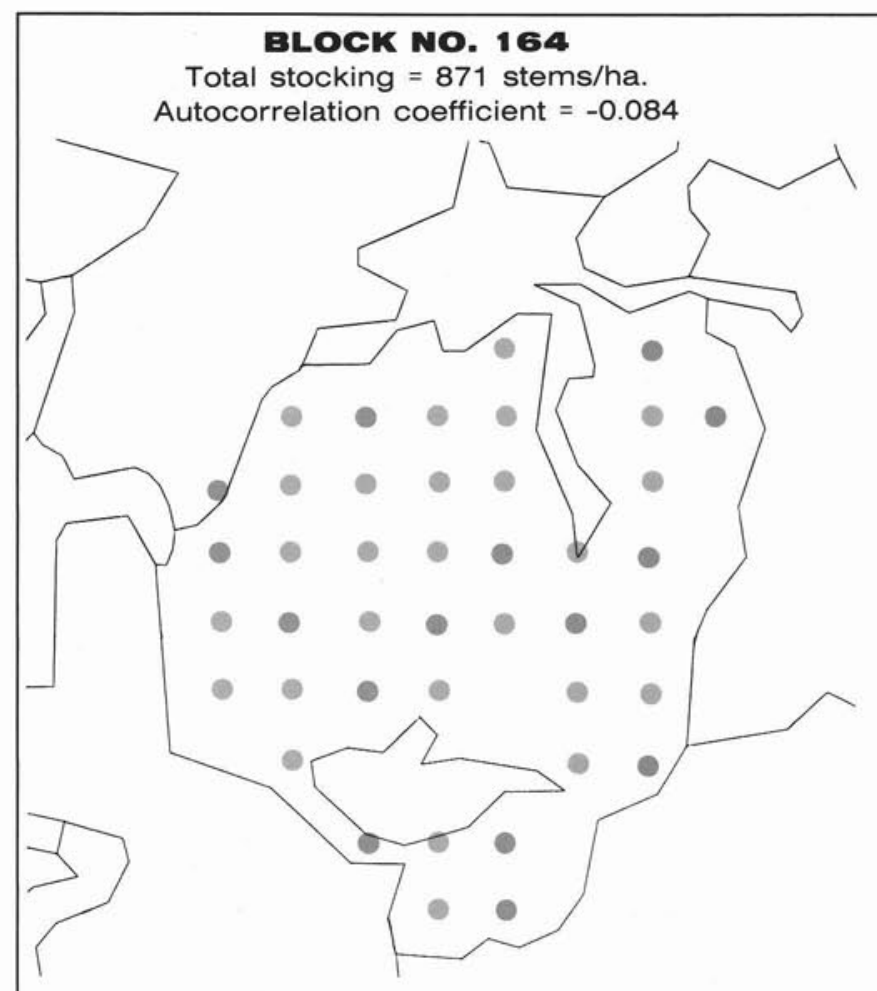

BLOCK NO. 151

Total stocking $=810$ stems $/$ ha.

Autocorrelation coefficient $=0.075$

Free-Growing stocking +725 stems/ha.

Autocorrelation coefficient +0.113
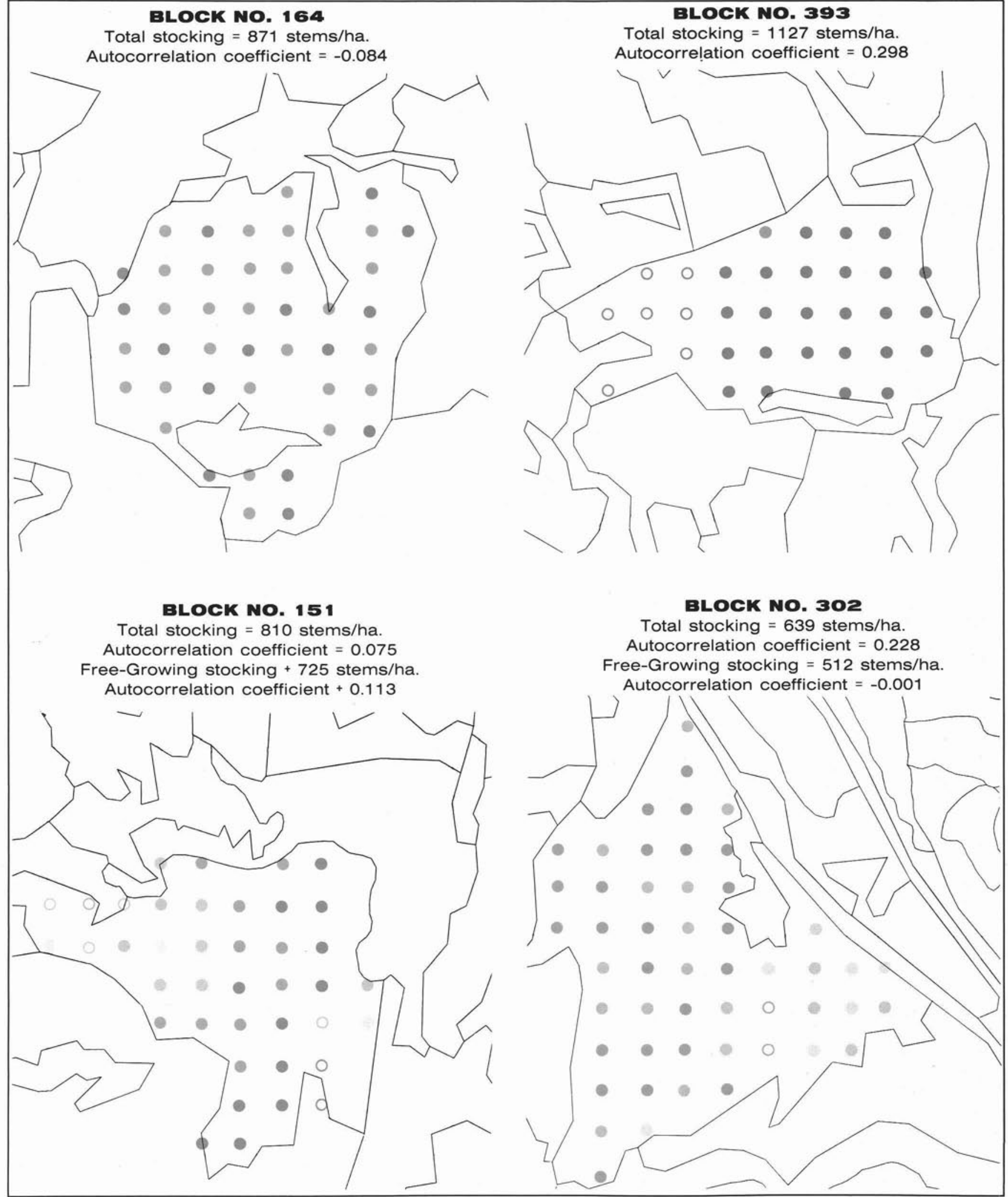

Figure 5. Output from the GIS displays the location of survey plots, coded by stocking class and free-growing stocking

a) Block $164-\mathrm{A}$ site with well-distributed free-growing status.

b) Block 393 - A site with sufficient average stocking, but poor spatial distribution (note positive I-stat value).

c) Block 302 - A site with poor stocking, but brush competition localized where release is least needed.

d) Block 151 - A site with good average stocking, but opportunity for significant benefit from brush control.

\section{VALUES IN \% FREE TO GROW}

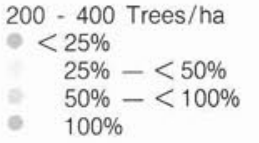

$600-1000$ Trees/ha $25 \%-<50 \%$ $50 \%-<100 \%$

- $100 \%$

1200 - 1600 Trees/ha - $<25 \%$

$25 \%-<50 \%$

$50 \%-<100 \%$

- $100 \%$ 
yields at rotation age. Work is now underway on a series of plots that were stem-mapped 30 to 50 years ago to examine the initial autocorrelation coefficient and current yields. If an approximate relationship between the early autocorrelation coefficient and later yields can be found, it will greatly improve the ability to justify the need for brush control or fill-planting in certain situations.

Work is also underway to determine the efficiency of early site index estimation. This will allow foresters to estimate site index at the free-growing stage and tie into models reflecting stocking, spatial pattern, and possibly even size distribution. The ability to determine the potential yield improvement from increased average stocking or decreased spatial autocorrelation would also pave the way for whole-forest models that apply economic and biological criteria to the ranking of different sites for treatment.

The GIS would also be particularly useful in this respect, because it could enable identification of sites with not only given brush or stocking problems, but also considerations relating to distance to mill, road access, or block size (Jordan 1986). The increasing quantities of data available and the complexity of decisions needed for effective silviculture planning will lead to development of decision support systems (Weetman 1987). With use of artificial intelligence systems, for example, silviculture opportunities could be ranked in value based on multiple criteria of timber supply projection, economic and budgetary factors, and individual site characteristics. This is parallel to an expert system described by Kourtz (1987), which schedules forest fire fighting activities based on individual fire 'force requirements' and the availability of resources.

Finally, while this paper concentrates on field-collected data, the rapid advances in remote sensing technology are allowing aerial survey with airborne linear array multispectral scanners to collect data at the individual tree level with a resolution of $30 \mathrm{~cm}$ (Leckie 1986). The implications of this are a quantum leap in both the quantity and quality of data used in decision-making. In future these technologies will radically improve the ability to make decisions at both the stand and forest level.

\section{HONDA 4 TRACK ALUMINUM RUNNING BOARDS}

\author{
Easy Installation \\ No Modification to Vehicle
}

$\$ 99.95$ plus shipping. Visa or C.O.D.

\author{
Contact: R S F Energy Ltd. \\ Box 3637, Smithers, B.C. \\ VOJ 2 NO \\ Tel.: (604) 847-4301
}

\section{Conclusions}

Foresters, faced with an increasing man-made forest estate, must become more efficient at collecting and using data. This is particularly true during the regeneration phase, when complex decisions must be made that affect the remainder of the rotation. The system presented here demonstrates that field survey data can be used more efficiently by combining data collection with summary and projection models, statistical analysis, and GIS software.

\section{Acknowledgements}

I would like to thank AI Den Haan, Eric Leskie and Leo Pilarski for programming assistance, Peter Janas for assistance with field testing, and Boyd Case, Tom Moore, Peter Kourtz and P.M. Corbett for manuscript review.

\section{References}

Baskerville, G.L. 1986. The state of forest research in Canada. Pp. 26-47 in The E.B. Eddy Distinguished Lecture Series. Fac. Forestry, Univ. Toronto.

Brand, D.G. and P.S. Janas. 1986. Regeneration performance survey system: System overview and user's manual. Internal Report, Petawawa National Forestry Institute, Chalk River, Ontario. 29 p.

Brand, D.G. and G.F. Weetman. 1986. Standards for regeneration establishment in Canada: A case study for Douglas-fir. For. Chron. 62: 84-90

Cliff, A.D. and J.K. Ord. 1981. Spatial Processes: Models and Applications. Pion Ltd., London, U.K. 266 p.

Jordan, G.A. 1986. Forest management planning with a geographic information system. Can. For. Ind. 71: 212-221.

Kourtz, P. 1987. Expert system dispatch of forest fire control resources. Al App. in Nat. Res. Manage. 1: 1-8.

Leckie, D.G. 1986. Practical forestry applications of remote sensing in North America: Present and future. Pp. 51-65 in Sohlberg, V.E. and Sokolov, V.E., (eds). 1986. Practical Applications of Remote Sensing in Forestry. Martinus Nijhoff, Boston.

Omule, S.A.Y. and G.J. Krumlik. 1987. Juvenile height growth of four species on four sites in the CWHb1 variant. Canada-BC Econ. \& Regional Dev. Agreement FRDA report 007, $15 \mathrm{p}$.

Thrower, J.S. 1986. Estimating site quality from early height growth of white spruce and red pine plantations in the Thunder Bay area. M.Sc.F. Thesis, Lakehead Univ. 143 p.

Weetman, G.F. 1987. Seven important determinants of Canadian silviculture. For. Chron. 63: 457-461.

\section{Journal Bargains for Institute Members!}

The Table of Contents of the Canadian Journal of Forest Research is carried every month in The Forestry Chronicle. Members are reminded that this prestigious forest research publication is available to them at a very special price of $\$ 33.00$ per year. The normal rate for Canadian individual subscribers for this Journal, direct from NRC is $\$ 70.00$ per year in Canada and $\$ 89.00$ per year in all other countries. Here then is another advantage of membership - a saving of $53 \%$ or $63 \%$ on the price of a subscription to Canadian Journal of Forest Research. Indeed, all NRC Journals are available to CIF Members at greatly reduced prices. Not for all members to be sure but a real saving for some.

Send your order and cheque to the National Office. 